\title{
The predictive value of different socio-economic indicators for overweight in nine European countries
}

\author{
Albert-Jan R Roskam* and Anton E Kunst \\ Erasmus MC, Department of Public Health, Room AE-141, Erasmus Medical Center, PO Box 2040, 3000 CA \\ Rotterdam, The Netherlands
}

Submitted 7 May 2007: Accepted 12 March 2008: First published online 29 May 2008

\begin{abstract}
Objectives: To assess which socio-economic indicator best predicts overweight in the European Union: educational attainment, occupational class or household income. Setting: The prevalence of overweight is strongly related to socio-economic position. The relative importance of different socio-economic dimensions is uncertain, and might vary between countries.

Design and subjects: Cross-sectional self-report data of the European Community Household Panel were obtained from nine countries ( $n$ 52 855; age 25-64 years). Uni- and multivariate regression analyses were employed to predict overweight $\left(\mathrm{BMI} \geq 25 \mathrm{~kg} / \mathrm{m}^{2}\right)$ in relationship to socio-economic indicators. Occupational class was measured using the new European Socioeconomic Classification.

Results: Large socio-economic differences in overweight were observed in all countries, especially for women. For both sexes, a low educational attainment was the strongest predictor of overweight. After controlling for education, overweight was negatively related to household income in women, but positively in men. Similar patterns were found for occupational class. For women, but not for men, educational inequalities in overweight were generally greater in Southern European countries. A similar pattern of inequalities in overweight was observed for all ages between 25 and 64 years.

Conclusions: Across Europe, overweight was more strongly and more consistently related to educational attainment than to occupational class or household income. People with lower educational attainment should be a specific target group for programmes and policies that aim to prevent overweight.
\end{abstract}

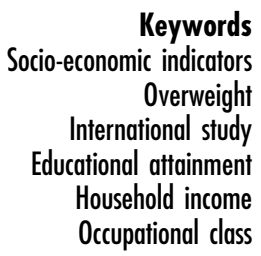

In Europe, overweight and obesity are estimated to account $8 \%$ of the overall burden of disease ${ }^{(1)}$ and $5 \%$ of the total health-care expenditures ${ }^{(2)}$. Numerous studies have shown that BMI differs by sociodemographic variables. A consistent finding is an inverse association of socio-economic position (SEP) with BMI, especially in females ${ }^{(3,4)}$.

The unequal distribution of overweight across socioeconomic groups offers an entry point for prevention activities. Overweight prevention approaches might be more cost-effective if they specifically target groups of lower SEP. However, SEP is a multidimensional construct of which individual components, such as educational attainment, occupational class or income level, represent different dimensions. These different dimensions do point to different mechanisms (e.g. different critical phases in the life course), and in addition they represent in part different groups of people. It is therefore important to know which aspect of SEP is most closely related to overweight.

In the present study, we were interested specifically in the magnitude of the independent effects that educational, income and occupational levels have on the prevalence of overweight. While many studies have reported associations between one SEP indicator and overweight, few studies have investigated the relative importance of different SEP indicators.

An American study that investigated simultaneously the associations between different components of SEP and researcher-measured body weight among women showed that there was a significant relationship between body weight and education, but not income ${ }^{(5)}$. Among men, the relationship with educational attainment was inconsistent, while a positive relationship between income and BMI was found ${ }^{(6)}$.

In the UK, lower occupational level predicted female obesity better than educational level or an indicator of material deprivation. The same study found that researcher-measured BMI was negatively related to income among men, while occupational level showed irregular patterns ${ }^{(7)}$.

Another study that used a pooled sample of men and women from fifteen countries of the European Union 
(EU) found that educational level had the greatest relative predictive value for self-reported obesity, compared with social class ${ }^{(8)}$. However, the measure of 'social class' was defined by level of income in some countries, while in others it was defined by occupation.

An Australian study found that researcher-measured BMI and SEP domains were associated ${ }^{(9)}$. Lower scores on the employment domain were associated with a higher risk of being overweight. However, educational attainment was not measured in that study.

The present study aimed to investigate the relative contribution of three complementary dimensions of SEP (educational attainment, household income, occupational class) to the risk of overweight. Data from the European Household Panel (ECHP) ${ }^{(10)}$ were used to measure inequalities in overweight across nine EU member states. The ECHP is a standardized, internationally comparable survey conducted using large samples. It contains detailed measurements of educational attainment, household income and occupational class. Occupational class was measured using the European Socioeconomic Classification (ESEC), a new and finely graded measure designed to enable better international comparability of the variable ${ }^{(11)}$.

We analysed our data in three major steps. First, we utilized the pooled data from all countries to analyse the relative contributions of each SEP in the EU at large. Second, we investigated variations between countries by stratifying the analysis per country. Third, we analysed the data by age group to assess variations between age groups in the relative importance of education, income and occupation. Men and women were analysed separately throughout.

\section{Experimental methods}

\section{Data sampling}

We used cross-sectional data of the ECHP conducted by Eurostat $^{(10)}$. The ECHP is a survey based on a standardized questionnaire, which is employed in the annual interviewing of a representative panel of households and non-institutionalized individuals aged 16 years and older in each EU member state. All surveys were based on a non-stratified random sampling design. All persons in the panel households were individually interviewed. The data collection was carried out in most EU countries by paper-and-pencil interviewing by national statistical institutes or research centres. The design, procedure ${ }^{(10,12)}$ and statistical issues ${ }^{(13)}$ of the ECHP have been described in more detail elsewhere.

Data used in the present study were from the survey conducted in 2000 (Wave 7). Data from nine member states of the EU were available for the analyses: Finland, Denmark, Belgium, Ireland, Austria, Italy, Spain, Greece and Portugal.

\section{Participants}

Basic information on the study population can be found in Table 1. A total of 52855 non-institutionalized persons (50.8\% females), aged 25 to 64 years, comprised the data set that was used in the analyses. The 25-64 years age range was selected because of the variations in age ranges available per country. Also, the validity of BMI as a measure for fat mass may be hampered in the elderly, as muscle mass may decrease above the age of 60 years ${ }^{(14)}$.

All countries except Ireland $(\sim 75 \%)$ had a response rate of above $80 \%$, while Greece, Italy and France obtained the highest response rates (>95\%). Main reasons for not responding were contact failure (person temporarily away) and lack of co-operation (inability or unwillingness to respond).

\section{Independent variables}

We utilized three SEP indicators: educational, occupational and income level. Educational attainment was defined as the highest level of general or higher education completed. Data were coded according to the International Standard Classification of Education (ISCED) ${ }^{(15)}$. This classification was designed to enable international comparability of educational systems. This variable had three descending levels: (i) recognized third-level education (corresponding to ISCED 5-7 or

Table 1 Sample sizes $(n)$, missing values* and age-adjusted prevalence of overweight and obesity $\left(\mathrm{BMI} \geq 25 \mathrm{~kg} / \mathrm{m}^{2}\right)$ and obesity $\left(\mathrm{BMI} \geq 30 \mathrm{~kg} / \mathrm{m}^{2}\right)$

\begin{tabular}{|c|c|c|c|c|c|c|c|c|}
\hline \multirow[b]{2}{*}{ Country } & \multicolumn{4}{|c|}{ Females } & \multicolumn{4}{|c|}{ Males } \\
\hline & $n$ & Missing (\%) & $\mathrm{BMI} \geq 25 \mathrm{~kg} / \mathrm{m}^{2}(\%)$ & $\mathrm{BMI} \geq 30 \mathrm{~kg} / \mathrm{m}^{2}(\%)$ & $n$ & Missing (\%) & $\mathrm{BMI} \geq 25 \mathrm{~kg} / \mathrm{m}^{2}(\%)$ & $\mathrm{BMI} \geq 30 \mathrm{~kg} / \mathrm{m}^{2}(\%)$ \\
\hline Finland & 2626 & $1 \cdot 6$ & $43 \cdot 1$ & $13 \cdot 5$ & 2621 & 0.7 & $57 \cdot 6$ & $12 \cdot 6$ \\
\hline Denmark & 1514 & $2 \cdot 6$ & $35 \cdot 7$ & $9 \cdot 3$ & 1483 & 0.6 & $50 \cdot 5$ & $11 \cdot 4$ \\
\hline Belgium & 1935 & $2 \cdot 7$ & $34 \cdot 2$ & $10 \cdot 9$ & 1753 & $2 \cdot 1$ & $52 \cdot 2$ & $11 \cdot 2$ \\
\hline Ireland & 2043 & $2 \cdot 3$ & $35 \cdot 0$ & $8 \cdot 3$ & 1994 & $2 \cdot 0$ & $56 \cdot 2$ & $9 \cdot 7$ \\
\hline Austria & 2200 & 1.9 & $36 \cdot 1$ & $9 \cdot 0$ & 2102 & 0.5 & $54 \cdot 4$ & $10 \cdot 1$ \\
\hline Italy & 5471 & $1 \cdot 1$ & $26 \cdot 8$ & $5 \cdot 0$ & 5443 & $1 \cdot 2$ & $49 \cdot 9$ & $8 \cdot 5$ \\
\hline Spain & 4302 & $8 \cdot 1$ & $35 \cdot 3$ & $9 \cdot 1$ & 4168 & $7 \cdot 1$ & $62 \cdot 7$ & $14 \cdot 8$ \\
\hline Greece & 3196 & $0 \cdot 1$ & $40 \cdot 6$ & $8 \cdot 2$ & 3065 & 0.7 & $65 \cdot 2$ & $11 \cdot 0$ \\
\hline Portugal & 3583 & $1 \cdot 1$ & $34 \cdot 3$ & $8 \cdot 1$ & 3356 & $2 \cdot 0$ & $54 \cdot 0$ & $8 \cdot 5$ \\
\hline Total & 26870 & $2 \cdot 5$ & $35 \cdot 7$ & $9 \cdot 1$ & 25985 & $2 \cdot 2$ & 55.9 & $10 \cdot 9$ \\
\hline
\end{tabular}

${ }^{*}$ No data for weight, height or both. 
$>12$ years of education); (ii) second stage of second-level education (ISCED 3 or 10-12 years of education); and (iii) less than second stage of second-level education (ISCED $0-2$ or $\leq 9$ years of education).

Occupational class was measured using the new ESEC scheme. The ESEC distinguishes nine social classes that differ in terms of employment relationships. It is an occupationally based classification that has rules to provide coverage of the whole adult population. The information required to assign people to these classes was: (i) occupation coded to the minor groups (i.e. 3-digit groups) of the International Standard Classification of Occupations 1988; (ii) details of employment status, i.e. whether an employer, self-employed or employee; (iii) number of employees at the workplace; and (iv) whether a worker is a supervisor ${ }^{(11)}$. Using this information, a total of nine quasi-hierarchical categories could be discerned (Table 2). Occupational class was assigned to each household member using the dominance approach ${ }^{(16)}$, which meant that the household member with the highest occupational class determined the class of each individual household member. Unclassifiable individuals were reported as 'ESEC unknown'.

Household income was defined as the pooled net household income divided by the square root of the number of persons in the household ${ }^{(17)}$. Each countryspecific sample was divided into income percentiles in order to: (i) enable international comparability of different currencies; and (ii) create a relative measure of poverty.

\section{Dependent variable}

BMI was defined as the self-reported weight (kilograms) divided by the squared self-reported height (metres). For most purposes, BMI $\left(\mathrm{kg} / \mathrm{m}^{2}\right)$ was categorized into the following categories: (i) underweight $(10 \leq \mathrm{BMI}<18)$; (ii) normal weight $(18 \leq \mathrm{BMI}<25)$; (iii) moderately overweight $(25 \leq \mathrm{BMI}<30)$; and (iv) obese $(\mathrm{BMI} \geq 30)$. BMI below $10 \mathrm{~kg} / \mathrm{m}^{2}$ was considered missing $(n 1)$. When BMI was dichotomized, the cut-off point was set at BMI $=25 \mathrm{~kg}$ / $\mathrm{m}^{2}$ (with $\mathrm{BMI} \geq 25 \mathrm{~kg} / \mathrm{m}^{2}$ referred to as 'overweight').

\section{Statistical analyses}

Prevalence rates were age-standardized using the direct method with the 1995 EU population as the standard. The prevalence ratio (PR) expresses the prevalence of overweight in the group of interest relative to the prevalence of overweight in the best-off socio-economic group. Prevalence ratios and their 95\% confidence intervals were estimated through regression with the log link function ${ }^{(18)}$ using the GENMOD procedure ${ }^{(19)}$ in the SAS/STAT statistical software package (SAS Institute Inc., Cary, NC, USA).

In the next step we summarized the association between overweight and each SEP indicator by calculating the Relative Index of Inequality (RII) and its 95\% confidence intervals ${ }^{(20-22)}$. RII is a regression-based measure that can be applied to each SEP indicator. It assesses the association between overweight ratios and the relative position of each socio-economic group separately. This relative position is measured as the cumulative proportion of each socio-economic group within the socio-economic hierarchy, with 0 and 1 as the extreme values. The resulting measure, the RII, can be interpreted as the risk of being overweight at the very top of the socio-economic hierarchy as compared with the very lowest end of the socio-economic hierarchy. An RII above (below) 1 indicates a negative (positive) relationship between SEP and overweight. The RII can be compared between the three SEP indicators, provided that a detailed and hierarchical classification is used for each indicator. In the same way, the RII can be used to make comparisons between countries and between age groups.

The RII was estimated with log linear regression with control for 5-year age group, using a methodology similar to that for the prevalence ratio estimations. We conducted two types of hierarchical analyses which controlled for: (i) age category and country (confounders) and one SEP indicator; or (ii) confounders and all SEP indicators. The last step aimed to eliminate the effect of the other SEP indicators on the association between the SEP indicator of interest and overweight prevalence.

\section{Results}

Table 1 shows that the overall prevalence of overweight $\left(\mathrm{BMI} \geq 25 \mathrm{~kg} / \mathrm{m}^{2}\right.$ ) was $35 \cdot 7 \%$ among females and $55.9 \%$ among males. Overweight was most prevalent in Greece and Finland (both sexes) and Spain (men). For women, the prevalence of overweight ranged from $26.8 \%$ in Italy to $43 \cdot 1 \%$ in Finland. For men, the prevalence of overweight ranged from $49.9 \%$ in Italy to $65.2 \%$ in Greece. Percentages of missing values were comparable between countries and were within the normal range $(\leq 2 \cdot 7 \%)$, with the exception of Spain $(8 \cdot 1 \%$ for women and $7 \cdot 1 \%$ for men).

Table 2 shows generally strong negative gradients for women, meaning that overweight prevalence rates increased sharply when SEP decreased. Based on prevalence ratios, this gradient was strongest for education. Differences between adjacent educational categories were significant. Controlling for the other SEP indicators caused an important reduction in educational differences in overweight. For example, the lowest educational group's PR was 2.76 before and 1.93 after controlling for the other SEP indicators.

Compared with educational level, occupational differences in overweight were smaller (and slightly irregular), but still pronounced. Controlling for the other SEP predictors only slightly reduced the predictive value of occupational class. Occupational class and overweight were more or less negatively linearly related, with slight irregularities in the gradient for the categories Lower 
Table 2 Proportional distribution, crude prevalence and prevalence ratios (PR) of overweight (BMI $\left.\geq 25 \mathrm{~kg} / \mathrm{m}^{2}\right)$ by class variables across Europe: females

\begin{tabular}{|c|c|c|c|c|c|c|}
\hline \multirow[b]{2}{*}{ Variable/Level } & \multirow[b]{2}{*}{ Proportion (\%) } & \multirow[b]{2}{*}{ Prevalence (\%) } & \multicolumn{2}{|c|}{ Model 1} & \multicolumn{2}{|c|}{ Model 2} \\
\hline & & & PR & $95 \% \mathrm{Cl}$ & PR & $95 \% \mathrm{Cl}$ \\
\hline \multicolumn{7}{|l|}{ Education } \\
\hline Highest $^{*}$ & $18 \cdot 3$ & $23 \cdot 1$ & $1 \cdot 00$ & - & 1.00 & - \\
\hline Mid & $30 \cdot 9$ & $29 \cdot 2$ & 1.59 & $1 \cdot 35,1 \cdot 87$ & $1 \cdot 27$ & $1 \cdot 16,1 \cdot 39$ \\
\hline Lowest & $50 \cdot 8$ & $48 \cdot 3$ & $2 \cdot 76$ & $2 \cdot 38,3 \cdot 22$ & 1.93 & $1 \cdot 75,2 \cdot 12$ \\
\hline \multicolumn{7}{|l|}{ Occupational class } \\
\hline Higher salariat* & $18 \cdot 6$ & $31 \cdot 1$ & $1 \cdot 00$ & - & $1 \cdot 00$ & - \\
\hline Lower salariat & $14 \cdot 6$ & $30 \cdot 3$ & 0.98 & $0 \cdot 85,1 \cdot 14$ & 1.04 & $0.95,1 \cdot 15$ \\
\hline Higher grade white collar & $11 \cdot 6$ & $31 \cdot 8$ & $1 \cdot 14$ & $0.97,1.34$ & $1 \cdot 01$ & $0 \cdot 91,1 \cdot 13$ \\
\hline Self-employed & $13 \cdot 3$ & $38 \cdot 2$ & 1.37 & $1 \cdot 19,1.57$ & $1 \cdot 15$ & $1 \cdot 04,1 \cdot 28$ \\
\hline Farmers & 5.9 & $49 \cdot \overline{9}$ & 1.07 & $0.89,1.29$ & $1 \cdot 25$ & $1 \cdot 10,1 \cdot 43$ \\
\hline Higher grade blue collar & $3 \cdot 1$ & $42 \cdot 5$ & $1 \cdot 44$ & $1 \cdot 15,1 \cdot 79$ & $1 \cdot 28$ & $1 \cdot 09,1 \cdot 51$ \\
\hline Lower grade white collar & $8 \cdot 5$ & $40 \cdot 7$ & $1 \cdot 32$ & $1 \cdot 11,1 \cdot 56$ & $1 \cdot 25$ & $1 \cdot 11,1 \cdot 40$ \\
\hline Skilled workers & $7 \cdot 8$ & $44 \cdot 8$ & $1 \cdot 28$ & $1.09,1.50$ & $1 \cdot 29$ & $1 \cdot 15,1 \cdot 46$ \\
\hline Routine & $8 \cdot 3$ & $46 \cdot 2$ & $1 \cdot 42$ & $1 \cdot 21,1 \cdot 67$ & $1 \cdot 34$ & $1 \cdot 19,1 \cdot 50$ \\
\hline ESEC unknown & $8 \cdot 3$ & $45 \cdot 3$ & $1 \cdot 08$ & $0 \cdot 89,1 \cdot 31$ & $1 \cdot 12$ & $0.99,1.26$ \\
\hline \multicolumn{7}{|l|}{ Income decile } \\
\hline Highest $^{*}$ & $9 \cdot 7$ & $27 \cdot 8$ & 1.00 & - & $1 \cdot 00$ & - \\
\hline P90 & $9 \cdot 6$ & 31.9 & $1 \cdot 20$ & $0.96,1.51$ & $1 \cdot 13$ & $1 \cdot 00,1 \cdot 29$ \\
\hline P80 & $9 \cdot 8$ & $34 \cdot 9$ & 1.66 & $1 \cdot 34,2 \cdot 06$ & $1 \cdot 28$ & $1.13,1.45$ \\
\hline P70 & $9 \cdot 8$ & $36 \cdot 8$ & $1 \cdot 75$ & $1 \cdot 41,2 \cdot 17$ & $1 \cdot 33$ & $1 \cdot 17,1 \cdot 51$ \\
\hline $\mathrm{P} 60$ & $9 \cdot 7$ & 38.9 & $2 \cdot 01$ & $1 \cdot 63,2 \cdot 49$ & 1.43 & $1 \cdot 26,1.63$ \\
\hline P50 & $9 \cdot 9$ & 39.5 & $1 \cdot 87$ & $1 \cdot 51,2 \cdot 31$ & $1 \cdot 40$ & $1.23,1.60$ \\
\hline P40 & $10 \cdot 0$ & $40 \cdot 7$ & $2 \cdot 61$ & $2 \cdot 13,3 \cdot 20$ & $1 \cdot 46$ & $1 \cdot 28,1.67$ \\
\hline P30 & $10 \cdot 3$ & $40 \cdot 9$ & $2 \cdot 24$ & $1 \cdot 83,2 \cdot 76$ & 1.45 & $1.28,1.66$ \\
\hline P20 & $10 \cdot 4$ & $42 \cdot 1$ & $2 \cdot 10$ & $1 \cdot 71,2 \cdot 58$ & $1 \cdot 46$ & $1.28,1.66$ \\
\hline Lowest & $10 \cdot 7$ & $43 \cdot 1$ & $2 \cdot 32$ & $1 \cdot 89,2 \cdot 84$ & 1.47 & $1.29,1.68$ \\
\hline
\end{tabular}

Model 1, overweight predicted by one socio-economic position (SEP) variable and corrected for age category and country (confounders); Model 2, Model $1+$ other SEP variables; ESEC, European Socioeconomic Classification (occupational class scheme).

${ }^{*}$ Reference category, therefore no $95 \% \mathrm{Cl}$ estimates (-).

salariat', 'Farmers' and 'Higher grade blue collar'. Most adjacent occupation categories were not significantly different from each other, but differences between the highest two occupational levels and the lowest three categories attained statistical significance.

The income-related gradient in overweight was relatively weak (and slightly irregular) but, like the occupational gradient, it remained pronounced. Controlling for the other SEP predictors caused a sharp reduction in the predictive value of income. There was an inverse relationship between income and overweight (less income, more overweight) within the poorest seven income deciles. The relationship was absent within the three richer deciles, i.e. the relationship flattened with increasing income. Only the highest two differed from the lowest two income deciles with statistical significance.

Table 3 shows the prevalence rates and prevalence ratios of overweight for male participants. After controlling for confounders and other SEP indicators, the prevalence ratios of overweight indicated that overweight was associated with lower education ( $P R=1 \cdot 48)$. For the other indicators, the patterns were irregular (occupation) or even slightly curvilinear (income). After controlling for other SEP predictors, the associations with income and occupational class were not statistically significant. Adjustment for other SEP indicators had virtually no effect on the predictive value of education.
Figure 1 shows a cross-country comparison of inequalities in overweight using the RII for education level, occupational class and household income, with mutual control among these SEP indicators. The first set of bars, which represents the pooled data, shows for either sex that the independent contribution to predict the likelihood of being overweight was greatest for education. The odds for women of being overweight was three times greater for the hypothetical lower end compared with the upper end of the educational hierarchy (RII = 2.98). For men, a similar but attenuated association was observed (RII $=1 \cdot 66)$.

For women in all countries, except in Denmark and Finland, education was the strongest predictor of inequality in overweight. In Denmark, occupational class was the strongest predictor. In Finland, the differences in the predictive value between the three indicators were negligible. Occupational level (RII $\cong 2$ ) was usually about half as predictive for overweight as educational level $(\mathrm{RII} \cong 3)$. Income level had the smallest independent effect in most countries. The magnitude of incomerelated inequalities in overweight, as expressed by the RII, ranged from 0.99 to $1 \cdot 78$, compared with $1 \cdot 39-4 \cdot 91$ for educational level and $1 \cdot 13-2 \cdot 37$ for occupational level.

For men, education was the strongest predictor of overweight in all countries. In most Southern European 
Table 3 Proportional distribution, crude prevalence and prevalence ratios (PR) of overweight $\left(\mathrm{BMI} \geq 25 \mathrm{~kg} / \mathrm{m}^{2}\right)$ by class variables across Europe: males

\begin{tabular}{|c|c|c|c|c|c|c|}
\hline \multirow[b]{2}{*}{ Variable/Level } & \multirow[b]{2}{*}{ Proportion (\%) } & \multirow[b]{2}{*}{ Prevalence (\%) } & \multicolumn{2}{|c|}{ Model 1} & \multicolumn{2}{|c|}{ Model 2} \\
\hline & & & PR & $95 \% \mathrm{Cl}$ & PR & $95 \% \mathrm{Cl}$ \\
\hline \multicolumn{7}{|l|}{ Education } \\
\hline Highest* & $17 \cdot 9$ & $49 \cdot 3$ & $1 \cdot 00$ & - & $1 \cdot 00$ & - \\
\hline Mid & $34 \cdot 2$ & $53 \cdot 8$ & $1 \cdot 32$ & $1 \cdot 22,1 \cdot 42$ & $1 \cdot 32$ & $1 \cdot 21,1 \cdot 43$ \\
\hline Lowest & $47 \cdot 9$ & $60 \cdot 7$ & 1.46 & $1 \cdot 36,1 \cdot 58$ & $1 \cdot 48$ & $1 \cdot 36,1 \cdot 61$ \\
\hline \multicolumn{7}{|l|}{ Occupational class } \\
\hline Higher salariat* & $19 \cdot 4$ & $54 \cdot 9$ & $1 \cdot 00$ & - & $1 \cdot 00$ & - \\
\hline Lower salariat & $14 \cdot 2$ & $52 \cdot 8$ & 0.96 & $0 \cdot 88,1 \cdot 05$ & 0.93 & $0.85,1.02$ \\
\hline Higher grade white collar & $10 \cdot 4$ & $53 \cdot 9$ & $1 \cdot 05$ & $0 \cdot 95,1 \cdot 15$ & 0.95 & $0.85,1.05$ \\
\hline Self-employed & $14 \cdot 4$ & $59 \cdot 8$ & $1 \cdot 21$ & $1 \cdot 10,1 \cdot 32$ & 1.09 & $0.99,1.19$ \\
\hline Farmers & $6 \cdot 7$ & $59 \cdot 9$ & $1 \cdot 10$ & $0 \cdot 98,1 \cdot 23$ & 0.98 & $0.87,1 \cdot 11$ \\
\hline Higher grade blue collar & $3 \cdot 5$ & $58 \cdot 3$ & $1 \cdot 21$ & $1 \cdot 04,1 \cdot 41$ & $1 \cdot 05$ & $0.90,1 \cdot 23$ \\
\hline Lower grade white collar & $7 \cdot 9$ & $58 \cdot 5$ & $1 \cdot 22$ & $1 \cdot 10,1 \cdot 37$ & 1.07 & $0.95,1.20$ \\
\hline Skilled workers & $9 \cdot 3$ & $55 \cdot 1$ & $1 \cdot 07$ & $0 \cdot 96,1 \cdot 18$ & 0.93 & $0.83,1.03$ \\
\hline Routine & $8 \cdot 4$ & $58 \cdot 8$ & $1 \cdot 19$ & $1 \cdot 07,1 \cdot 32$ & $1 \cdot 04$ & $0 \cdot 93,1 \cdot 16$ \\
\hline ESEC unknown & $5 \cdot 8$ & $54 \cdot 9$ & 0.98 & $0 \cdot 87,1 \cdot 11$ & 0.91 & $0.80,1 \cdot 04$ \\
\hline \multicolumn{7}{|l|}{ Income decile } \\
\hline Highest* & $10 \cdot 3$ & $55 \cdot 7$ & $1 \cdot 00$ & - & $1 \cdot 00$ & - \\
\hline P90 & $10 \cdot 4$ & $54 \cdot 9$ & 1.03 & $0 \cdot 92,1 \cdot 15$ & 0.96 & $0.86,1.08$ \\
\hline P80 & $10 \cdot 3$ & $55 \cdot 8$ & $1 \cdot 07$ & $0 \cdot 96,1 \cdot 20$ & 0.98 & $0.87,1.09$ \\
\hline P70 & $10 \cdot 4$ & $57 \cdot 6$ & $1 \cdot 16$ & $1 \cdot 03,1 \cdot 29$ & 1.03 & $0.92,1 \cdot 16$ \\
\hline P60 & $10 \cdot 3$ & $56 \cdot 1$ & $1 \cdot 10$ & $0.98,1 \cdot 23$ & 0.96 & $0.86,1.08$ \\
\hline P50 & $10 \cdot 1$ & $57 \cdot 8$ & $1 \cdot 19$ & $1 \cdot 06,1 \cdot 33$ & $1 \cdot 03$ & $0.91,1 \cdot 16$ \\
\hline P40 & $10 \cdot 0$ & $58 \cdot 2$ & $1 \cdot 17$ & $1 \cdot 04,1 \cdot 31$ & $1 \cdot 00$ & $0 \cdot 88,1 \cdot 12$ \\
\hline P30 & $9 \cdot 7$ & $57 \cdot 8$ & $1 \cdot 18$ & $1 \cdot 06,1 \cdot 33$ & $1 \cdot 00$ & $0 \cdot 89,1 \cdot 13$ \\
\hline P20 & $9 \cdot 4$ & $55 \cdot 2$ & $1 \cdot 07$ & $0 \cdot 95,1 \cdot 20$ & 0.90 & $0.79,1.01$ \\
\hline Lowest & $9 \cdot 1$ & $53 \cdot 6$ & 0.97 & $0.86,1.09$ & $0 \cdot 81$ & $0.72,0.92$ \\
\hline
\end{tabular}

Model 1, overweight predicted by one socio-economic position (SEP) variable and corrected for age category and country (confounders); Model 2, Model 1 + other SEP variables; ESEC, European Socioeconomic Classification (occupational class scheme).

${ }^{*}$ Reference category, therefore no $95 \% \mathrm{Cl}$ estimates $(-)$.

countries (Italy, Greece, Spain) the magnitude of educational inequality was relatively small compared with nonSouthern countries. In most countries (except Austria and Italy), income was positively related to overweight. Differences in overweight according to occupational class were generally small and inconsistent in terms of directionality.

Figure 2 shows inequalities in overweight in four age groups using the RII for education level, occupational class and household income. Among women, education was the strongest predictor for overweight in all age groups. Compared with younger age groups, educational inequalities in overweight were much smaller in the oldest age group (55-64 years). Inequalities according to occupational class showed no clear variation between age groups. Household income showed smaller inequalities in the older age groups.

Among men, the pattern of inequalities in overweight was fairly similar between age groups. Level of education was negatively related to the prevalence of overweight in all age groups. Similar to women, educational level was also the strongest predictor for overweight. None of the age groups showed a systematic relationship between occupational class and overweight. Overweight was slightly positively related to income in all age groups, except for the youngest age quartile (in which a gradient was absent).

\section{Discussion}

\section{Summary}

Our study revealed education attainment as a stronger predictor for overweight, especially among women, as compared with occupational class and household income. This finding holds for most EU countries and all age categories. For women, occupational class and income levels both show a relatively weak and negative relationship to overweight. For men, the same relationship was found between occupational level and overweight, while income level was weakly positively related to overweight (i.e. more overweight at higher income levels).

\section{Data and methods evaluation}

People with a high true BMI have a tendency to underreport their weight ${ }^{(23)}$. Given that people of low SEP are over-represented in higher BMI categories, underreporting may occur more frequently in lower SEP persons. However, there is no evidence that at any level of weight the level of under-reporting of weight depends on the SEP indicator used. Estimates of relative inequalities in overweight (such as the RII) may therefore remain unaffected even though absolute levels of overweight are underestimated. However, we acknowledge that we cannot entirely exclude the possibility that the various 

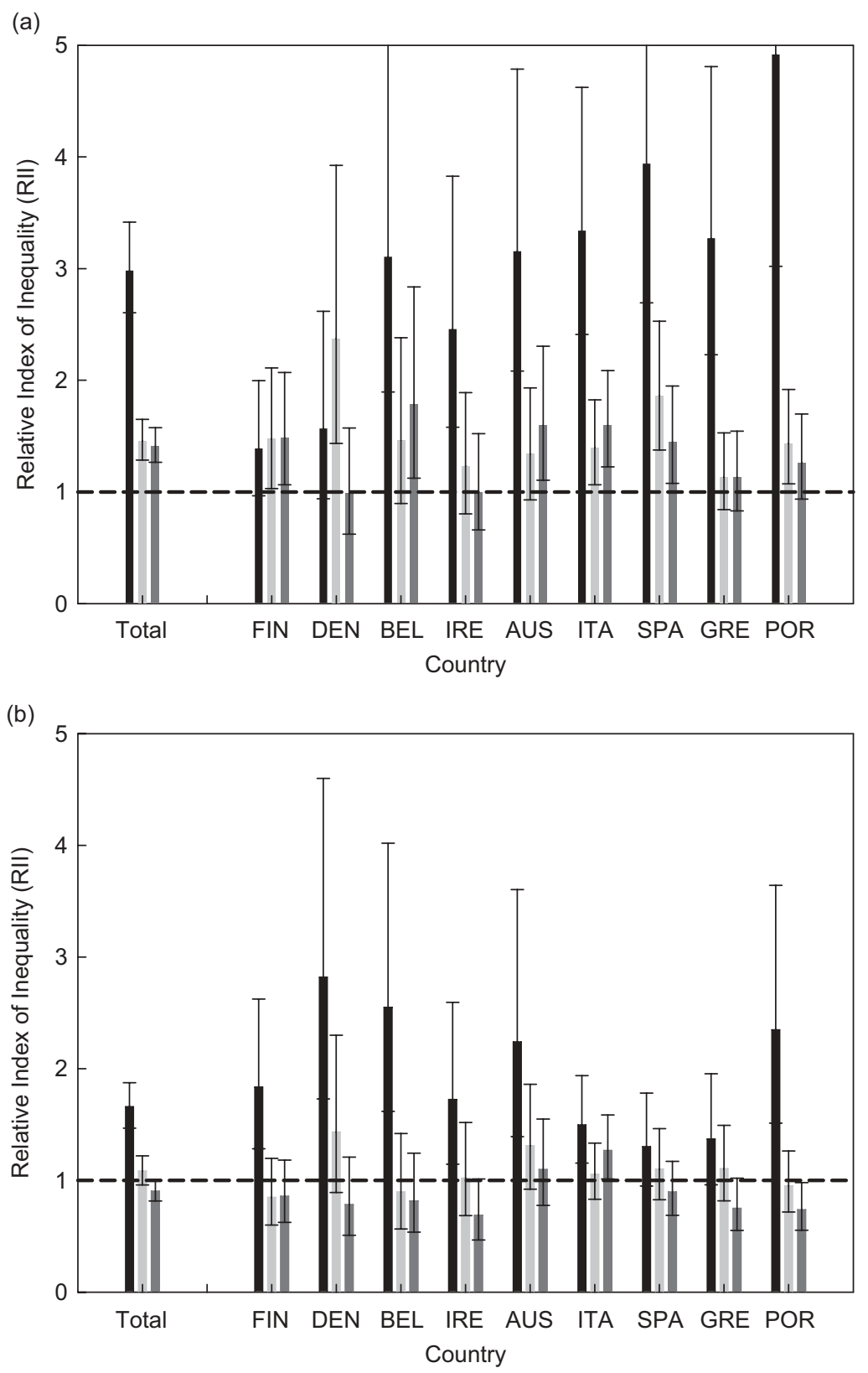

Fig. 1 Inequalities in overweight for females (a) and males (b), measured using educational level (left bar), occupational level (middle bar) or income level (right bar). Error bars indicate the $95 \%$ confidence interval. Histogram bars that do not extend above the horizontal dashed line indicate a positive gradient between socio-economic position and overweight (FIN, Finland; DEN, Denmark; BEL, Belgium; IRE, Ireland; AUS, Austria; ITA, Italy; SPA, Spain; GRE, Greece; POR, Portugal)

SEP indicators differentially predict under-reporting of height and weight.

Ethnicity appears to influence BMI independently of educational level ${ }^{(24,25)}$. We evaluated the possible confounding effect of ethnicity by excluding foreign-born respondents (1005 women and 877 men) from our regression analyses. Migrants were defined as being born abroad or being born in the present country but having lived in a different country. The educational inequalities were notably larger among migrant women $\left(\mathrm{RII}_{\text {migrants }}=6 \cdot 24\right)$, but their exclusion did not substantially influence the observed patterns $\left(\mathrm{RII}_{\text {non-migrants }}=2 \cdot 82\right.$ and $\left.\mathrm{RII}_{\text {total }}=2 \cdot 98\right)$.

Countries differ strongly in their educational systems and this may have led to problems regarding the comparability of educational classifications. Part of the international variation in the predictive value of education may therefore be an unavoidable classification artefact: the lowest educational level in country A may not be equal to that in country B. Income (being intrinsically quantitative in nature) and occupation (being measured 


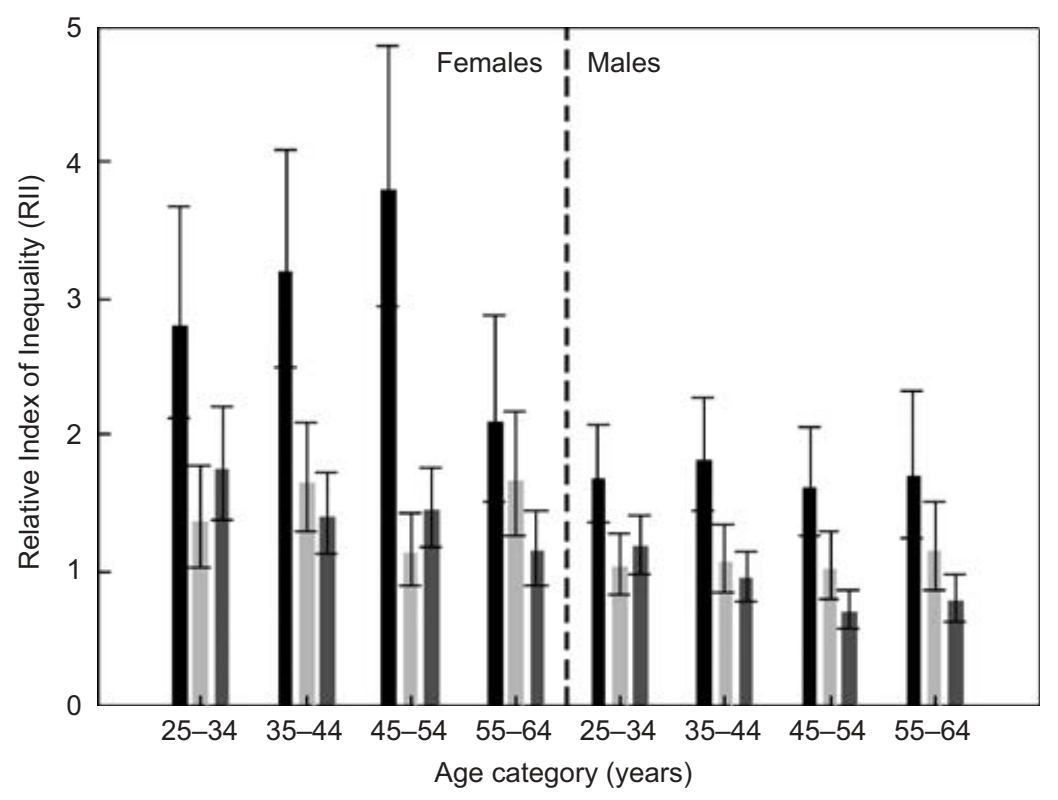

Fig. 2 Country-adjusted inequalities in overweight for females and males of different age categories, measured using educational level (left bar), occupational level (middle bar) or income level (right bar). Error bars indicate the $95 \%$ confidence interval. Histogram bars that do not extend above the horizontal dashed line indicate a positive gradient between socio-economic position and overweight

with an internationally validated instrument) may be less sensitive to this comparability problem. Nevertheless, for the majority of countries, educational attainment appeared to be the best predictor of overweight. Also, this was observed when deploying the RII, a measure that could be applied in a comparable way to each country and each socio-economic indicator with a detailed hierarchical classification.

To improve international comparability, educational level was measured according to only three standard categories. This rather crude categorization implies that there may be a significant educational heterogeneity within each category. The observed educational inequalities may have been greater with the use of a more finely graded educational categorization, especially within the lower educational levels. If so, this would imply that educational attainment would perform even better (as compared with occupation class and household income) in predicting variations in overweight.

\section{Comparison with previous studies}

The observed gender differences in the association between SEP and overweight are consistent with previous findings ${ }^{(4)}$ and suggest that educational aspects of SEP impact differentially on body weight for men and women.

In accordance with our findings, Flegal et al. ${ }^{(5)}$ observed that the relative importance of education for the prediction of BMI was greater compared with income. A study that used a large sample of EU citizens also revealed educational level to have a stronger association with obesity than surrogate measures of occupational class ${ }^{(8)}$.
Sarlio-Lahteenkorva et $a l^{(26)}$ found that educational inequalities in obesity were greater than occupational inequalities in Finland among men and women, but in Denmark only among men.

Our findings support these and some other findings ${ }^{(27)}$. However, we are the first to show that a greater predictive power of educational level is observed almost consistently for each sex, country and age group. Moreover, we deployed standardized instruments in our study for the measurement of educational attainment, occupational class and household income, thus reducing measurement bias.

UK research reported occupational level as the strongest independent predictor of obesity among women, but not among men ${ }^{(7)}$. Even though we observed similar results for some cases (e.g. women in Denmark), our results imply that the findings of this British study do not represent a generalized pattern.

\section{Explanation and interpretation of results}

Why is educational attainment so strongly related to overweight? A higher predictive value of educational level as compared with the other SEP indicators was observed for most populations across all parts of Western Europe. The persistency of this pattern suggests that causes of inequalities in overweight are intimately linked with educational level.

Both environmental and genetic factors might underlie the association between SEP and BMI. From a large twin study, genetic factors were concluded to be the main determinants of education-based BMI differences ${ }^{(28)}$. 


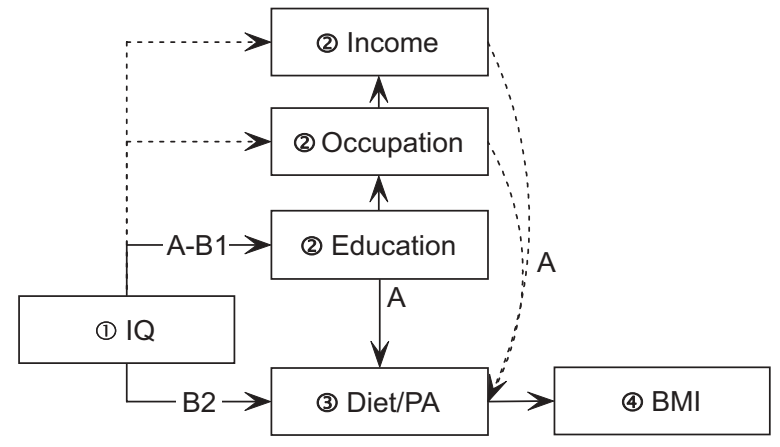

Fig. 3 Model relating intelligence (1), socio-economic position (2) and BMI (4) and its determinants, diet and physical activity (3). Lines labelled A represent a mediator pathway; lines labelled B a moderator pathway. Dashed lines indicate relationships that are relatively small according to the present study and its interpretation (IQ, intelligence quotient; SEP, socio-economic position; PA, physical activity)

Intelligence was identified as one potential explanation for the correlation between education and $\mathrm{BMI}^{(29)}$.

The possible interrelationships of intelligence, SEP and BMI and its determinants are presented in Fig. 3. There is a strong positive correlation between intelligence and educational attainment. Education in turn provides people with skills and knowledge to function in society and thus to achieve attain higher occupational position and income levels. Intelligence constitutes a marginal (but in itself insufficient) condition for the acquisition of skills and knowledge that are important for preventing overweight through appropriate lifestyles ${ }^{(30)}$.

From this perspective, intelligence may moderate the relationship between SEP and overweight. The effects of health promotion messages, for example, may be less effective for those groups or populations with lower intelligence, which could in turn contribute to greater educational inequalities in diets and levels of physical activity, thereby contributing to greater inequalities in BMI.

In addition to this modifying effect, the relationship between childhood intelligence and obesity may be largely mediated via educational attainment and the other socio-economic indicators $^{(31)}$ (arrow A in Fig. 3). Lawlor et $a l^{(32)}$ found that the inverse association between childhood intelligence and adult BMI was largely attenuated by adjustment for educational attainment.

In conclusion, higher intelligence may set in motion a protective chain of events that leads to a reduction in later-life obesity risk $^{(33)}$. General cognitive abilities may represent more favourable outcomes in terms of education (but to a lesser extent occupation and income) and body weight. Within this chain, educational attainment may also exert an important independent effect on BMI. Educational attainment, hence, may be a better predictor of the behavioural, cognitive and attitudinal correlates of overweight than occupational and income levels. Also, education precedes the other two SEP indicators and is therefore more likely to exert a greater cumulative effect.

On the other hand, our results also suggest that occupational class and income exert an additional effect independent from educational level ${ }^{(7)}$. Income may be weakly related to overweight through access to material resources. Individuals with higher incomes have more options in food access and food choices as well as in voluntary energy expenditure, although actual energy intake may not vary by income ${ }^{(34)}$. Occupational class as defined in the ESEC is related to overweight despite relatively small differences between occupational levels in industrialized societies in the amount of physical labour performed in the job. ESEC classes differ in terms of intrinsic job characteristics, including level of support, long-term economic security and sense of control ${ }^{(35)}$. Social relationships at work may differ in more specific ways, such as the extent to which social pressures favour or disfavour excessive eating and favour physical exercise. Through these psychosocial factors, people's occupational class may exert an additional effect on overweight independent of educational level.

Strong secular changes in the association between SEP and BMI have occurred in a relatively short period ${ }^{(36,37)}$, which suggests a crucial role for the environment. An underlying predisposition to overweight may or may not become manifest depending on the environment as a factor. Thus, the 'obesogenic' environment may have triggered overweight in vulnerable individuals, and an increase in knowledge about the harmful effects of overweight may have had a protective effect on others.

Why are the educational inequalities in overweight among women greater in Southern Europe? In Portugal, Spain, Italy and Greece, the proportion of persons in the lowest educational category is much greater (67\%) than in the other countries $(35 \%)^{(38)}$. Also, the expenditure per student on tertiary education is about $80 \%$ higher in the Northern European countries included in our study ${ }^{(39)}$. These differences may reflect variations in the quality and of national educational systems. Those with the lowest educational level in Southern Europe may be lower in terms of knowledge acquisition than those in the rest of Europe. When a certain minimum educational level of education cannot be acquired by a relatively large part of the population, this may yield larger educational inequalities in overweight.

The above explanations still do not answer the question why this mechanism would selectively impact women. Variations in the levels of educational participation between the two regions are slightly larger for women ${ }^{(40)}$. Perhaps more importantly, the fact that overweight is far more stigmatized in women than in men ${ }^{(41)}$ may further increase the 'overweight gap', thus augmenting cross-national differences in educational inequalities overweight. 


\section{Implications and conclusion}

The results suggest that the educational dimension of SEP is much more strongly related to overweight than the occupational or income dimensions. This is crucial for understanding inequalities in overweight and for developing strategies and interventions to prevent overweight in lower socio-economic groups ${ }^{(42)}$.

Causes of inequalities in overweight must primarily be thought of as inequalities in cognitive, attitudinal and cultural factors that are best approximated by the level of education. People with lower educational attainment should be a specific target group for programmes and policies that aim to prevent overweight. These groups may benefit from a focus on health literacy, aimed at increasing their understanding of and ability to modify behaviours with regard to diet and physical activity ${ }^{(7)}$.

\section{Acknowledgements}

The present investigation received funding support from the Health \& Consumer Protection Directorate-General of the European Union and was carried out as a part of the EUROTHINE project (grant no. 2003125) and the Eurocadet Project (grant no. SP23-CT-2005-006528). A.-J.R.R. and A.E.K. were both responsible for the refinement of the research question and the analysis plan, the interpretation of results, and the writing. A.-J.R.R. was responsible for the actual data analysis and write-up of the manuscript. A.E.K. coordinated the analysis and edited the manuscript. A.E.K. also co-managed the EUROTHINE project.

The authors declare no conflict of interest.

\section{References}

1. Pomerleau J, McKee M, Lobstein T \& Knai C (2003) The burden of disease attributable to nutrition in Europe. Public Health Nutr 6, 453-461.

2. Visscher TL \& Seidell JC (2001) The public health impact of obesity. Annu Rev Public Health 22, 355-375.

3. McLaren L (2007) Socioeconomic status and obesity. Epidemiol Rev 29, 29-48.

4. Sobal J \& Stunkard AJ (1989) Socioeconomic status and obesity: a review of the literature. Psychol Bull 105, 260-275.

5. Flegal KM, Harlan WR \& Landis JR (1988) Secular trends in body mass index and skinfold thickness with socioeconomic factors in young adult women. Am J Clin Nutr 48, 535-543.

6. Flegal KM, Harlan WR \& Landis JR (1988) Secular trends in body mass index and skinfold thickness with socioeconomic factors in young adult men. Am J Clin Nutr $\mathbf{4 8}$, 544-551.

7. Wardle J, Waller J \& Jarvis MJ (2002) Sex differences in the association of socioeconomic status with obesity. Am J Public Health 92, 1299-1304.

8. Martinez JA, Kearney JM, Kafatos A, Paquet S \& MartinezGonzalez MA (1999) Variables independently associated with self-reported obesity in the European Union. Public Health Nutr 2, 125-133.
9. Ball K, Mishra G \& Crawford D (2002) Which aspects of socioeconomic status are related to obesity among men and women? Int J Obes Relat Metab Disord 26, 559-565.

10. Eurostat (1999) European Community Housebold Panel, Users' Database Manual. Luxemburg: Eurostat.

11. Harrison E \& Rose D (2006) The European Socio-economic Classification (ESEC) - Draft User Guide. Colchester, UK: University of Essex.

12. Peracchi F (2002) The European Community Household Panel: a review. Emp Econ 63-90.

13. Office for Official Publications of the European Communities (2005) Statistical Analysis on Health-related Longitudinal Data from the ECHP. Luxemburg: European Commission.

14. Seidell JC \& Visscher TL (2000) Body weight and weight change and their health implications for the elderly. Eur J Clin Nutr 54, S33-S39.

15. United Nations Educational, Scientific and Cultural Organization (1997) International Standard Classification of Education (ISCED). Paris: UNESCO Institute for Statistics.

16. Erikson R (1984) Social class of men, women and families. Sociology 18, 500-514.

17. Huisman M, Kunst AE \& Mackenbach JP (2003) Socioeconomic inequalities in morbidity among the elderly; a European overview. Soc Sci Med 57, 861-873.

18. Skov T, Deddens J, Petersen MR \& Endahl L (1998) Prevalence proportion ratios: estimation and hypothesis testing. Int J Epidemiol 27, 91-95.

19. SAS Institute, Inc (1999) SAS/STAT User's Guide, 8.2 ed. Cary, NC: SAS Institute, Inc.

20. Mackenbach JP \& Kunst AE (1997) Measuring the magnitude of socio-economic inequalities in health: an overview of available measures illustrated with two examples from Europe. Soc Sci Med 44, 757-771.

21. Sergeant JC \& Firth D (2006) Relative index of inequality: definition, estimation, and inference. Biostatistics 7, 213-224.

22. Macintyre S, Der G \& Norrie J (2005) Are there socioeconomic differences in responses to a commonly used self report measure of chronic illness? Int J Epidemiol 34, $1284-1290$.

23. Ziebland S, Thorogood M, Fuller A \& Muir J (1996) Desire for the body normal: body image and discrepancies between self reported and measured height and weight in a British population. J Epidemiol Community Health 50, 105-106.

24. Sundquist J \& Johansson SE (1998) The influence of socioeconomic status, ethnicity and lifestyle on body mass index in a longitudinal study. Int J Epidemiol 27, 57-63.

25. Winkleby MA, Gardner CD \& Taylor CB (1996) The influence of gender and socioeconomic factors on Hispanic/white differences in body mass index. Prev Med 25, 203-211.

26. Sarlio-Lahteenkorva S, Lissau I \& Lahelma E (2006) The social patterning of relative body weight and obesity in Denmark and Finland. Eur J Public Health 16, 36-40.

27. Galobardes B, Morabia A \& Bernstein MS (2000) The differential effect of education and occupation on body mass and overweight in a sample of working people of the general population. Ann Epidemiol 10, 532-537.

28. Silventoinen K, Sarlio-Lahteenkorva S, Koskenvuo M, Lahelma E \& Kaprio J (2004) Effect of environmental and genetic factors on education-associated disparities in weight and weight gain: a study of Finnish adult twins. Am J Clin Nutr 80, 815-822.

29. Teasdale TW, Sorensen TI \& Stunkard AJ (1992) Intelligence and educational level in relation to body mass index of adult males. Hum Biol 64, 99-106. 
30. Huisman M, Kunst AE \& Mackenbach JP (2005) Intelligence and socioeconomic inequalities in health. Lancet 366, 807-808.

31. Halkjaer J, Holst C \& Sorensen TI (2003) Intelligence test score and educational level in relation to BMI changes and obesity. Obes Res 11, 1238-1245.

32. Lawlor DA, Clark H, Davey Smith G \& Leon DA (2006) Childhood intelligence, educational attainment and adult body mass index: findings from a prospective cohort and within sibling-pairs analysis. Int $J$ Obes (Lond) 30, 1758-1765.

33. Chandola T, Deary IJ, Blane D \& Batty GD (2006) Childhood IQ in relation to obesity and weight gain in adult life: the National Child Development (1958) Study. Int J Obes (Lond) 30, 1422-1432.

34. Sobal J (1991) Obesity and socioeconomic status: a framework for examining relationships between physical and social variables. Med Anthropol 13, 231-247.

35. Wardle J, Steptoe A, Oliver G \& Lipsey Z (2000) Stress, dietary restraint and food intake. J Psychosom Res $\mathbf{4 8}$, 195-202.

36. Molarius A, Seidell JC, Sans S, Tuomilehto J \& Kuulasmaa K (2000) Educational level, relative body weight, and changes in their association over 10 years: an international perspective from the WHO MONICA Project. Am J Public Health 90, 1260-1268.

37. Torrance GM, Hooper MD \& Reeder BA (2002) Trends in overweight and obesity among adults in Canada (1970-1992): evidence from national surveys using measured height and weight. Int J Obes Relat Metab Disord 26, 797-804

38. Eurostat (2001) Eurostat Labour Force Survey. Luxembourg: Office for Official Publications of the European Communities.

39. Organization for Economic Cooperation and Development (2002) Education at a Glance, OECD Indicators. Paris: OECD.

40. United Nations Economic Commission for Europe (2001) Trends in Europe and North America - The Statistical Yearbook of the Economic Commission for Europe 2001. Geneva: United Nations Publications.

41. Gordon RA (1990) Anorexia and Bulimia: Anatomy of a Social Epidemic. Cambridge, MA: Basil Blackwell.

42. Gurka MJ, Wolf AM, Conaway MR, Crowther JQ, Nadler JL \& Bovbjerg VE (2006) Lifestyle intervention in obese patients with type 2 diabetes: impact of the patient's educational background. Obesity (Silver Spring) 14, 1085-1092.

\section{Appendix - Supplementary information}

Table A Prevalence (\%) of overweight and by socio-economic position (SEP) and age group for males and females

\begin{tabular}{|c|c|c|c|c|c|c|c|c|}
\hline \multirow[b]{3}{*}{ SEP indicator/Level } & \multicolumn{4}{|c|}{ Females } & \multicolumn{4}{|c|}{ Males } \\
\hline & \multicolumn{4}{|c|}{ Age group (years) } & \multicolumn{4}{|c|}{ Age group (years) } \\
\hline & $25-34$ & $35-44$ & $45-54$ & $55-64$ & $25-34$ & $35-44$ & $45-54$ & $55-64$ \\
\hline \multicolumn{9}{|l|}{ Education } \\
\hline Highest & $15 \cdot 4$ & $20 \cdot 5$ & $30 \cdot 7$ & $43 \cdot 6$ & $36 \cdot 7$ & $48 \cdot 1$ & $57 \cdot 9$ & $57 \cdot 5$ \\
\hline Mid & $18 \cdot 4$ & $26 \cdot 8$ & $39 \cdot 4$ & $47 \cdot 0$ & $39 \cdot 9$ & $55 \cdot 3$ & $63 \cdot 0$ & $66 \cdot 2$ \\
\hline Lowest & $26 \cdot 4$ & $39 \cdot 8$ & $52 \cdot 3$ & $58 \cdot 5$ & $46 \cdot 3$ & $58 \cdot 6$ & $64 \cdot 4$ & $65 \cdot 1$ \\
\hline \multicolumn{9}{|l|}{ Occupation } \\
\hline Higher salariat & $15 \cdot 1$ & $23 \cdot 7$ & $41 \cdot 1$ & $48 \cdot 7$ & $38 \cdot 8$ & $52 \cdot 4$ & $62 \cdot 5$ & $66 \cdot 2$ \\
\hline Lower salariat & $17 \cdot 6$ & 24.9 & $35 \cdot 3$ & $51 \cdot 5$ & $38 \cdot 0$ & $52 \cdot 7$ & $60 \cdot 3$ & $58 \cdot 9$ \\
\hline Higher grade white collar & $17 \cdot 0$ & $27 \cdot 3$ & $44 \cdot 4$ & $50 \cdot 1$ & $41 \cdot 7$ & $54 \cdot 3$ & $59 \cdot 3$ & $64 \cdot 3$ \\
\hline Self-employed & $19 \cdot 6$ & $34 \cdot 1$ & $48 \cdot 5$ & $55 \cdot 6$ & $44 \cdot 3$ & $58 \cdot 3$ & $67 \cdot 3$ & $69 \cdot 0$ \\
\hline Farmers & $27 \cdot 8$ & $39 \cdot 6$ & $56 \cdot 5$ & $60 \cdot 7$ & $46 \cdot 7$ & $56 \cdot 5$ & $65 \cdot 5$ & $64 \cdot 4$ \\
\hline Higher grade blue collar & $25 \cdot 9$ & $36 \cdot 3$ & $49 \cdot 5$ & $56 \cdot 7$ & $45 \cdot 7$ & $55 \cdot 7$ & $69 \cdot 4$ & 63.5 \\
\hline Lower grade white collar & $23 \cdot 5$ & $37 \cdot 5$ & $50 \cdot 9$ & $58 \cdot 8$ & $45 \cdot 7$ & $59 \cdot 3$ & $64 \cdot 4$ & $67 \cdot 6$ \\
\hline Skilled workers & $28 \cdot 6$ & $36 \cdot 9$ & $51 \cdot 0$ & $62 \cdot 3$ & $40 \cdot 2$ & $54 \cdot 8$ & $63 \cdot 2$ & $62 \cdot 7$ \\
\hline Routine & $24 \cdot 9$ & $43 \cdot 2$ & $51 \cdot 7$ & $61 \cdot 1$ & $44 \cdot 2$ & $59 \cdot 5$ & $60 \cdot \overline{9}$ & $66 \cdot 5$ \\
\hline \multicolumn{9}{|l|}{ Income quintile } \\
\hline Highest & $11 \cdot 9$ & $22 \cdot 2$ & $37 \cdot 6$ & $46 \cdot 2$ & $37 \cdot 9$ & 53.5 & $63 \cdot 3$ & $63 \cdot 6$ \\
\hline Second-highest & $17 \cdot 9$ & $27 \cdot 5$ & $44 \cdot 5$ & $56 \cdot 8$ & $40 \cdot 7$ & $54 \cdot 1$ & $66 \cdot 1$ & $66 \cdot 3$ \\
\hline Middle & $22 \cdot 0$ & $31 \cdot 8$ & $48 \cdot 8$ & $57 \cdot 1$ & $43 \cdot 5$ & $55 \cdot 5$ & $62 \cdot 4$ & $66 \cdot 5$ \\
\hline Second-lowest & $21 \cdot 9$ & $36 \cdot 0$ & $49 \cdot 6$ & $59 \cdot 3$ & $43 \cdot 8$ & $57 \cdot 6$ & $62 \cdot 2$ & $67 \cdot 4$ \\
\hline Lowest & $25 \cdot 2$ & $36 \cdot 3$ & $51 \cdot 3$ & $57 \cdot 0$ & $42 \cdot 2$ & $54 \cdot 7$ & $59 \cdot 0$ & $59 \cdot 3$ \\
\hline Total & $20 \cdot 1$ & $31 \cdot 1$ & $45 \cdot 7$ & $55 \cdot 5$ & $41 \cdot 6$ & $55 \cdot 2$ & $62 \cdot 8$ & $64 \cdot 5$ \\
\hline
\end{tabular}


Table B Prevalence (\%) of overweight $\left(\mathrm{BMI} \geq 25 \mathrm{~kg} / \mathrm{m}^{2}\right)$ across various countries: females

\begin{tabular}{|c|c|c|c|c|c|c|c|c|c|c|}
\hline \multirow[b]{2}{*}{ SEP indicator/Level } & \multicolumn{9}{|c|}{ Country* } & \multirow[b]{2}{*}{ Tota } \\
\hline & FIN & DEN & BEL & IRE & AUS & ITA & SPA & GRE & POR & \\
\hline \multicolumn{11}{|l|}{ Education } \\
\hline Highest & $36 \cdot 1$ & $28 \cdot 5$ & $22 \cdot 5$ & $24 \cdot 7$ & $21 \cdot 5$ & $17 \cdot 0$ & $22 \cdot 8$ & $29 \cdot 2$ & $26 \cdot 5$ & $26 \cdot 8$ \\
\hline Mid & $42 \cdot 4$ & $34 \cdot 9$ & $31 \cdot 8$ & $36 \cdot 6$ & 33.9 & $22 \cdot 3$ & $31 \cdot 5$ & 38.9 & $24 \cdot 5$ & $32 \cdot 1$ \\
\hline Lowest & $45 \cdot 7$ & $40 \cdot 9$ & 43.9 & $41 \cdot 0$ & $47 \cdot 9$ & $36 \cdot 1$ & $45 \cdot 1$ & $48 \cdot 8$ & $47 \cdot 1$ & $43 \cdot 5$ \\
\hline \multicolumn{11}{|l|}{ Occupation } \\
\hline Higher salariat & $34 \cdot 2$ & $23 \cdot 8$ & $25 \cdot 4$ & $30 \cdot 2$ & $31 \cdot 0$ & $25 \cdot 2$ & $26 \cdot 1$ & $41 \cdot 7$ & $37 \cdot 3$ & $30 \cdot 9$ \\
\hline Lower salariat & $38 \cdot 3$ & $35 \cdot 8$ & $26 \cdot 9$ & $34 \cdot 8$ & $34 \cdot 5$ & $26 \cdot 6$ & $29 \cdot 0$ & $32 \cdot 2$ & $34 \cdot 0$ & $31 \cdot 3$ \\
\hline Higher grade white collar & $40 \cdot 9$ & $35 \cdot 1$ & $28 \cdot 3$ & $39 \cdot 0$ & $36 \cdot 7$ & $25 \cdot 0$ & $34 \cdot 8$ & $38 \cdot 7$ & $33 \cdot 6$ & $33 \cdot 4$ \\
\hline Self-employed & $48 \cdot 3$ & $35 \cdot 3$ & $29 \cdot 2$ & $40 \cdot 6$ & $34 \cdot 4$ & $30 \cdot 6$ & $40 \cdot 8$ & $42 \cdot 9$ & $43 \cdot 1$ & $38 \cdot 4$ \\
\hline Farmers & $42 \cdot 1$ & $25 \cdot 8$ & $40 \cdot 6$ & $42 \cdot 0$ & $44 \cdot 5$ & $27 \cdot 9$ & $51 \cdot 5$ & $45 \cdot 3$ & $47 \cdot 3$ & $45 \cdot 0$ \\
\hline Higher grade blue collar & $41 \cdot 1$ & $37 \cdot 3$ & $38 \cdot 4$ & $40 \cdot 9$ & $38 \cdot 2$ & $38 \cdot 9$ & $47 \cdot 3$ & $36 \cdot 7$ & $41 \cdot 8$ & $42 \cdot 0$ \\
\hline Lower grade white collar & $45 \cdot 9$ & $43 \cdot 1$ & $41 \cdot 8$ & $39 \cdot 5$ & $38 \cdot 6$ & $34 \cdot 5$ & $45 \cdot 3$ & $46 \cdot 2$ & $43 \cdot 9$ & $42 \cdot 2$ \\
\hline Skilled workers & $48 \cdot 9$ & $37 \cdot 6$ & $51 \cdot 9$ & $42 \cdot 5$ & $39 \cdot 9$ & $32 \cdot 2$ & $46 \cdot 1$ & $50 \cdot 1$ & $51 \cdot 2$ & 43.9 \\
\hline Routine & $42 \cdot 3$ & $39 \cdot 8$ & $41 \cdot 8$ & $40 \cdot 4$ & $51 \cdot 1$ & $42 \cdot 7$ & $45 \cdot 9$ & $46 \cdot 3$ & $50 \cdot 2$ & $44 \cdot 7$ \\
\hline ESEC unknown & $35 \cdot 7$ & $30 \cdot 4$ & $43 \cdot 6$ & $32 \cdot 9$ & $32 \cdot 9$ & $32 \cdot 5$ & $43 \cdot 3$ & $50 \cdot 7$ & $51 \cdot 1$ & $38 \cdot 0$ \\
\hline \multicolumn{11}{|l|}{ Income quintile } \\
\hline Highest & $38 \cdot 9$ & $30 \cdot 9$ & $22 \cdot 1$ & $29 \cdot 1$ & $26 \cdot 7$ & $23 \cdot 4$ & $26 \cdot 2$ & $35 \cdot 4$ & $30 \cdot 3$ & $28 \cdot 3$ \\
\hline Second-highest & $38 \cdot 8$ & $30 \cdot 4$ & $24 \cdot 6$ & $39 \cdot 9$ & $37 \cdot 4$ & $27 \cdot 5$ & $38 \cdot 9$ & $39 \cdot 5$ & $43 \cdot 2$ & $35 \cdot 2$ \\
\hline Middle & $42 \cdot 2$ & $36 \cdot 5$ & $32 \cdot 3$ & $38 \cdot 7$ & $37 \cdot 8$ & $30 \cdot 2$ & $41 \cdot 3$ & $45 \cdot 3$ & $46 \cdot 4$ & 38.9 \\
\hline Second-lowest & $45 \cdot 0$ & $36 \cdot 9$ & $35 \cdot 7$ & $37 \cdot 7$ & $42 \cdot 8$ & $32 \cdot 5$ & $42 \cdot 8$ & $45 \cdot 7$ & $47 \cdot 8$ & $40 \cdot 7$ \\
\hline Lowest & $43 \cdot 2$ & $35 \cdot 4$ & $41 \cdot 8$ & $39 \cdot 3$ & $39 \cdot 6$ & $36 \cdot 8$ & $44 \cdot 9$ & $48 \cdot 7$ & $47 \cdot 5$ & $42 \cdot 0$ \\
\hline Total & $43 \cdot 1$ & $35 \cdot 7$ & $34 \cdot 2$ & $35 \cdot 0$ & $36 \cdot 1$ & $26 \cdot 8$ & $35 \cdot 3$ & $40 \cdot 6$ & $34 \cdot 3$ & $35 \cdot 7$ \\
\hline
\end{tabular}

SEP, socio-economic position; ESEC, European Socioeconomic Classification (occupational class scheme).

*FIN, Finland; DEN, Denmark; BEL, Belgium; IRE, Ireland; AUS, Austria; ITA, Italy; SPA, Spain; GRE, Greece; POR, Portugal.

Table C Prevalence (\%) of overweight $\left(\mathrm{BMI} \geq 25 \mathrm{~kg} / \mathrm{m}^{2}\right)$ across various countries: males

\begin{tabular}{|c|c|c|c|c|c|c|c|c|c|c|}
\hline \multirow[b]{2}{*}{ SEP indicator/Level } & \multicolumn{9}{|c|}{ Country* } & \multirow[b]{2}{*}{ Total } \\
\hline & FIN & DEN & BEL & IRE & AUS & ITA & SPA & GRE & POR & \\
\hline \multicolumn{11}{|l|}{ Education } \\
\hline Highest & $51 \cdot 6$ & $39 \cdot 9$ & $43 \cdot 9$ & $50 \cdot 2$ & $40 \cdot 3$ & $41 \cdot 0$ & $57 \cdot 3$ & $61 \cdot 7$ & $52 \cdot 2$ & $50 \cdot 0$ \\
\hline Mid & $57 \cdot 1$ & $50 \cdot 5$ & $53 \cdot 8$ & $57 \cdot 4$ & $56 \cdot 1$ & $50 \cdot 0$ & $64 \cdot 8$ & $64 \cdot 8$ & $49 \cdot 3$ & $55 \cdot 6$ \\
\hline Lowest & $60 \cdot 6$ & $58 \cdot 5$ & $54 \cdot 9$ & $58 \cdot 8$ & $61 \cdot 0$ & $53 \cdot 9$ & $62 \cdot 0$ & $65 \cdot 8$ & $58 \cdot 3$ & $59 \cdot 1$ \\
\hline \multicolumn{11}{|l|}{ Occupation } \\
\hline Higher salariat & $53 \cdot 3$ & $42 \cdot 4$ & $50 \cdot 1$ & $55 \cdot 6$ & $55 \cdot 2$ & $49 \cdot 9$ & $56 \cdot 7$ & $63 \cdot 9$ & $58 \cdot 9$ & $54 \cdot 4$ \\
\hline Lower salariat & $59 \cdot 1$ & $48 \cdot 3$ & $47 \cdot 0$ & $53 \cdot 4$ & $47 \cdot 8$ & $46 \cdot 6$ & $65 \cdot 6$ & $58 \cdot 0$ & $51 \cdot 4$ & $51 \cdot 8$ \\
\hline Higher grade white collar & $61 \cdot 6$ & $51 \cdot 6$ & $57 \cdot 0$ & $53 \cdot 8$ & $50 \cdot 1$ & $44 \cdot 7$ & $61 \cdot 4$ & $66 \cdot 8$ & $55 \cdot 7$ & $54 \cdot 7$ \\
\hline Self-employed & $67 \cdot 2$ & $53 \cdot 5$ & $43 \cdot 5$ & $61 \cdot 5$ & $59 \cdot 6$ & $54 \cdot 3$ & $61 \cdot 5$ & $65 \cdot 8$ & $59 \cdot 0$ & $59 \cdot 4$ \\
\hline Farmers & $51 \cdot 2$ & $73 \cdot 0$ & $58 \cdot 2$ & $57 \cdot 0$ & $58 \cdot 5$ & $49 \cdot 3$ & $64 \cdot 5$ & $67 \cdot 2$ & $58 \cdot 7$ & $58 \cdot 6$ \\
\hline Higher grade blue collar & $55 \cdot 5$ & $49 \cdot 1$ & $50 \cdot 0$ & $68 \cdot 6$ & $61 \cdot 5$ & $55 \cdot 5$ & $58 \cdot 3$ & $57 \cdot 2$ & $72 \cdot 1$ & $58 \cdot 7$ \\
\hline Lower grade white collar & $64 \cdot 4$ & $61 \cdot 9$ & $46 \cdot 0$ & $57 \cdot 8$ & $62 \cdot 4$ & $54 \cdot 3$ & $61 \cdot 6$ & $62 \cdot 2$ & $59 \cdot 7$ & $59 \cdot 5$ \\
\hline Skilled workers & $50 \cdot 5$ & $48 \cdot 3$ & $56 \cdot 3$ & $56 \cdot 9$ & $59 \cdot 4$ & $51 \cdot 0$ & $62 \cdot 5$ & $64 \cdot 1$ & $54 \cdot 8$ & $55 \cdot 8$ \\
\hline Routine & $53 \cdot 4$ & $57 \cdot 1$ & $59 \cdot 1$ & $53 \cdot 5$ & $58 \cdot 5$ & $54 \cdot 7$ & $63 \cdot 0$ & $67 \cdot 1$ & $60 \cdot 1$ & $58 \cdot 4$ \\
\hline ESEC unknown & $47 \cdot 2$ & $45 \cdot 4$ & $48 \cdot 1$ & $61 \cdot 5$ & $48 \cdot 8$ & $54 \cdot 9$ & $55 \cdot 1$ & $64 \cdot 8$ & $39 \cdot 3$ & $52 \cdot 9$ \\
\hline \multicolumn{11}{|l|}{ Income quintile } \\
\hline Highest & $60 \cdot 7$ & $49 \cdot 1$ & $47 \cdot 3$ & $56 \cdot 0$ & $51 \cdot 6$ & $47 \cdot 7$ & $60 \cdot 5$ & $63 \cdot 8$ & $55 \cdot 7$ & $54 \cdot 2$ \\
\hline Second-highest & $58 \cdot 4$ & $48 \cdot 9$ & $52 \cdot 0$ & $59 \cdot 0$ & $54 \cdot 3$ & $50 \cdot 0$ & $60 \cdot 8$ & $64 \cdot 3$ & $59 \cdot 9$ & $56 \cdot 2$ \\
\hline Middle & $55 \cdot 6$ & $53 \cdot 8$ & $50 \cdot 6$ & $57 \cdot 3$ & $58 \cdot 0$ & $51 \cdot 1$ & $62 \cdot 9$ & $66 \cdot 2$ & $58 \cdot 6$ & $57 \cdot 1$ \\
\hline Second-lowest & $57 \cdot 4$ & $48 \cdot 3$ & $51 \cdot 9$ & $59 \cdot 2$ & $61 \cdot 2$ & $53 \cdot 0$ & $63 \cdot 2$ & $64 \cdot \overline{5}$ & $57 \cdot 8$ & $57 \cdot 8$ \\
\hline Lowest & $55 \cdot 2$ & $48 \cdot 3$ & $49 \cdot 2$ & $52 \cdot 1$ & 51.9 & $52 \cdot 6$ & $58 \cdot 1$ & $62 \cdot 7$ & $53 \cdot 5$ & $54 \cdot 4$ \\
\hline Total & $57 \cdot 6$ & $50 \cdot 5$ & $52 \cdot 2$ & $56 \cdot 2$ & $54 \cdot 4$ & $49 \cdot 9$ & $62 \cdot 7$ & $65 \cdot 2$ & $54 \cdot 0$ & $55 \cdot 9$ \\
\hline
\end{tabular}

SEP, socio-economic position; ESEC, European Socioeconomic Classification (occupational class scheme).

*FIN, Finland; DEN, Denmark; BEL, Belgium; IRE, Ireland; AUS, Austria; ITA, Italy; SPA, Spain; GRE, Greece; POR, Portugal. 